\title{
Antifungal Activity of Hinokitiol-Related Compounds on Wood-Rotting Fungi and Their Insecticidal Activities
}

\author{
Yoshihiko Inamori,,${ }^{*} a$ Yoshikazu Sakagami, ${ }^{b}$ Yasuhiro Morita,${ }^{c}$ Mitsunobu Shibata, ${ }^{d}$ \\ Masaaki Sugiura, ${ }^{d}$ Yuko Kumeda, ${ }^{b}$ Toshihiro OKabe, ${ }^{e}$ Hiroshi Tsusibo, ${ }^{a}$ and Nakao IshidA ${ }^{f}$ \\ Osaka University of Pharmaceutical Sciences, ${ }^{a}$ 4-20-1 Nasahara, Takatsuki, Osaka 569-1041, Japan, Osaka Prefectural \\ Institute of Public Health, ${ }^{b}$ 1-3-69 Nakamichi, Higashinari-ku, Osaka 537-0025, Japan, Osaka Organic Chemical \\ Industry Ltd.," 18-8 Katayama-cho, Kashiwara, Osaka 582-0020, Japan, Fumakilla Ltd.," Ono-cho, Saiki-gun, Hiroshima \\ 739-0494, Japan, Industrial Research Institute of Aomori Prefecture, 80 Fukuromachi, Hirosaki, Aomori 036-8363, \\ Japan, and The Sendai Institute of Microbiology, ICR Building 2F, 6-6-3 Minamiyoshinari Aoba-ku, Sendai 989-3204, \\ Japan. Received January 19, 2000; accepted April 20, 2000
}

Hinokitiol ( $\beta$-thujaplicin), $\beta$-dolabrin and $\gamma$-thujaplicin isolated from Thujopsis dolabrata SIEB. et Zucc. var hondai MAKINo showed antifungal activities against all of the wood-rotting fungi examined. The antifungal activity of three compounds on Daedalea dickinsii IFO-4979 was especially strong, their minimum inhibitory concentration (MIC) values being $0.2 \mu \mathrm{g} / \mathrm{ml}$. Their antifungal activities on $D$. dickinsii IFO-4979 were as high as that of amphotericin B used as a positive control. Three compounds had strong insecticidal activities on Tyrophagus putrescentiae [ $50 \%$-lethal concentration $\left(\mathrm{LC}_{50}: \mathrm{g} / \mathrm{m}^{2}\right) 0.25$ in hinokitiol, 0.02 in $\beta$-dolabrin and $\gamma$-thujaplicin]. Their insecticidal activities were higher than that of $N, N$-diethyl-m-toluamide $\left(D E E T, L C_{50}: 1.46 \mathrm{~g} / \mathrm{m}^{2}\right.$ ) used as a positive control. Three compounds also showed strong insecticidal activity on Coptotermes formosanus $\left[\mathrm{LC}_{50}\left(\mathrm{~g} / \mathrm{m}^{2}\right)\right.$ 0.07 in hinokitiol, 0.05 in $\beta$-dolabrin and $\gamma$-thujaplicin], although their insecticidal activities were much lower than that of commercial chloropyrifos $\left(\mathrm{LC}_{50}: 0.00016 \mathrm{~g} / \mathrm{m}^{2}\right)$.

Key words hinokitiol; $\beta$-dolabrin; $\gamma$-thujaplicin; antifungal activity; wood-rotting fungus; insecticidal activity

Konjiki-do, a well-known national treasure, is one of the buildings in Chusonji Temple in Hiraizumi, Iwate-ken, Japan. In the year 1124 A.D., Konjiki-do was built of Aomori-Hiba (Thujopsis dolabrata SIEB et ZuCC. var hondai MAKINO) ${ }^{1)}$ and thereafter, this building was kept from harm by the noxious insects and the wood-rotting fungi ${ }^{2)}$ for a long period of about eight hundred years, until it was extensively repaired in the year 1962 A.D. At least part of the reason for this property of long endurance of Konjiki-do seems to be the growth-inhibitory activity of the constituents of $T$. dolabrata SIEB. et ZuCC. var hondai MAKINO on the noxious insects and wood-rotting fungi, ${ }^{2)}$ although the complete reason is not yet known. With regard to the insecticidal activity of the constituents of $T$. dolabrata SiEB. et ZuCC. var hondai MAKINO, there was a patent ${ }^{3)}$ issued for hinokitiol ${ }^{4)}$ (Chart 1 ), the major component of this plant, for use as a repellent for mites. It was also reported in another patent ${ }^{5)}$ that tropolone, ${ }^{6)}$ which has a basic skeleton in common with hinokitiol, was used to prevent the spread of termites on logs. However, no work has been done on the insecticidal activity of $\beta$-dolabrin or $\gamma$-thujaplicin (Chart 1), constituents of $T$. dolabrata SiEB. et Zucc. var hondai MAKINO on noxious insects. Although hinokitiol has been found to show the antifungal activity against two kinds of wood-rotting fungi, ${ }^{2,7)}$ no study has been done on the similar activity of $\beta$-dolabrin and $\gamma$-thujaplicin.

In this work, as a preliminary step to determine the reasons for the endurance of Konjiki-do, the antifungal activity of $\beta$-dolabrin and $\gamma$-thujaplicin against five kinds of woodrotting fungi was investigated and compared with that of hinokitiol. The insecticidal activity of $\beta$-dolabrin and $\gamma$-thujaplicin against Tyrophagus putrescentiae and Coptotermes formosanus was examined in comparison with that of hinokitiol.

\section{MATERIALS AND METHODS}

Chemicals Hinokitiol $(1.0 \%),{ }^{8)} \beta$-dolabrin $(1.0 \%)^{8)}$ and $\gamma$-thujaplicin ${ }^{8)}(0.2 \%)$ isolated from acid oil obtained by distillation of the wood of $T$. dolabrata SiEB. et Zucc. var hondai MAKINO according to the method of Nozoe et al. ${ }^{9)}$ were used for the various activity tests. As the yield of $\gamma$-thujaplicin was too small to permit examination of biological activity, this compound chemically synthesized was kindly supplied by Takasago Int. Corp. Hinokitiol-acetate ${ }^{8)}$ prepared in the usual manner was used as the comparative agent for the various biological activity tests. Amphotericin B (a positive control for antifungal activity) was purchased from BristolMyers Squibb Co., Ltd. $N, N$-Diethyl- $m$-toluamide (DEET, a positive control for insecticidal activity test on Tyrophagus putrescentiae) was obtained from Yoshitomi Pharmaceutical Industries, Ltd., Osaka, Japan. Chloropyrifos (a positive control for insecticidal activity test on Coptotermes formosanus) was purchased from Hoechst Schering Agro Evo, Japan, Ltd., Osaka, Japan.

Microorganisms Fungi: Fungi used for the antifungal activity test on the wood-rotting fungi were as follows: Pycnoporus coccineus IFO-4924, Schizophyllum commune IFO4928, Coriolus versicolor IFO-4940, Lenzites betulina IFO-

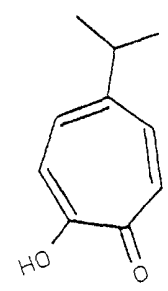

$\gamma$-Thujaplicin

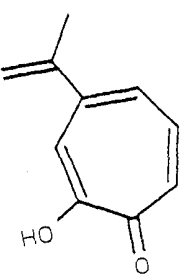

$\beta$-Dolabrin

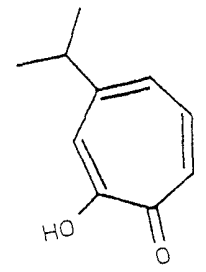

Hinokitiol ( $\beta$-Thujaplicin)
Chart 1 
Table 1. Antifungal Activity of Hinokitiol, $\beta$-Dolabrin and $\gamma$-Thujaplicin on Wood-Rotting Fungi

\begin{tabular}{|c|c|c|c|c|}
\hline \multirow{2}{*}{ Fungus } & \multicolumn{4}{|c|}{$\operatorname{MIC}(\mu \mathrm{g} / \mathrm{ml})^{a)}$} \\
\hline & Hinokitiol & $\beta$-Dolabrin & $\gamma$-Thujaplicin & Amphotericin B \\
\hline Daedalea dickinsii IFO-4979 & 0.2 & 0.2 & 0.2 & 0.39 \\
\hline Coriolus vericolor IFO-4940 & 12.5 & 6.25 & 6.25 & 0.39 \\
\hline Schizophyllum commune IFO-4928 & 12.5 & 12.5 & 12.5 & 0.39 \\
\hline Lenzites betulina IFO-4964 & 12.5 & 12.5 & 12.5 & 0.39 \\
\hline Pycnoporus coccineus IFO-4924 & 12.5 & 25.0 & 25.0 & 0.78 \\
\hline
\end{tabular}

a) Minimum inhibitory concentration. Assay: agar dilution method. Medium: The mixture of potato dextrose agar "Nissul" (A) and Staphylococcus medium "Eiken" (B) was used. Ratio of $\mathrm{A}$ and $\mathrm{B}$ was adjusted to $4: 1$. Culture condition: $25^{\circ} \mathrm{C}$ for $7 \mathrm{~d}$.

\section{4 and Daedalea dickinsii IFO-4979.}

Insects Insects used for the insecticidal activity test were as follows: Tyrophagus putrescentiae and Coptotermes formosanus. T. putrescentiae was purchased from Japan Environmental Sanitation Center. C. formosanus was collected at Wakayama-shi in Wakayama-ken, Japan.

Method The antifungal activity of hinokitiol, $\beta$-dolabrin and $\gamma$-thujaplicin on the wood-rotting fungi was investigated by the agar dilution method. The insecticidal activity of the three compounds on T. putrescentiae was examined according to the clip method. ${ }^{10)}$ The insecticidal activity on C. formosanus was investigated according to the following method. A test solution was prepared by dissolving each compound in acetone. One milliliter of the solution was dripped onto $9 \mathrm{~cm}$ diameter filter papers, then dried in air. The filter papers were then laid in $9 \mathrm{~cm}$ petri dishes. A glass ring with a diameter of $7 \mathrm{~cm}$ was put on the papers into which C. formosanus were released. To prevent drying, cotton was dipped in water and stuck on the lid of the petri dish into which the insects were released. Mortality was counted $24 \mathrm{~h}$ and $48 \mathrm{~h}$ after treatment.

\section{RESULTS AND DISCUSSION}

As shown in Table 1, the three compounds showed antifungal activity against all of the wood-rotting fungi examined, although their antifungal activities on other fungi examined except for $D$. dickinsii IFO-4979 were lower than that of amphotericin B used as a positive control. Their antifungal activities on $D$. dickinsii IFO-4979 were especially strong, their minimum inhibitory concentration (MIC) being 0.2 $\mu \mathrm{g} / \mathrm{ml}$; this was as high as that of amphotericin B which was used as a positive control. This is of considerable interest, although the reason for this finding is not clear at present. The facts suggest that the antifungal activity on the wood-rotting fungi might be a common biological activity of hinokitiol-related compounds. Although hinokitiol has already been reported to show not only the antimicrobial activity on pathogenic fungi or plant pathogenic fungi, ${ }^{8,11-137}$ but also growthinhibitory activity on the wood-rotting fungi, ${ }^{2,7)}$ this activity of $\beta$-dolabrin and $\gamma$-thujaplicin is reported for the first time in this paper.

Results of the insecticidal activity of hinokitiol, $\beta$-dolabrin and $\gamma$-thujaplicin on T. putrescentiae using the clip method ${ }^{10)}$ are summarized in Table 2. On filter paper, the three compounds showed strong insecticidal activities against this insect. The mortalities of hinokitiol were $91.3 \%$ and $33.6 \%$ at $0.5 \mathrm{~g} / \mathrm{m}^{2}$ and $0.2 \mathrm{~g} / \mathrm{m}^{2}$, respectively, and its $50 \%$-lethal con-
Table 2. Insecticidal Activity of Hinokitiol, $\beta$-Dolabrin and $\gamma$-Thujaplicin on Tyrophagus putrescentiae

\begin{tabular}{ccccc}
\hline \hline $\begin{array}{c}\text { Concentration } \\
\left(\mathrm{g} / \mathrm{m}^{2}\right)\end{array}$ & Hinokitiol & $\beta$-Dolabrin & $\gamma$-Thujaplicin & $\begin{array}{c}N, N \text {-Diethyl- } \\
m \text {-toluamide }\end{array}$ \\
\hline 1.00 & 100.0 & 100.0 & 100.0 & 67.1 \\
0.50 & 91.3 & 100.0 & 100.0 & 18.9 \\
0.20 & 77.5 & 100.0 & 100.0 & 4.5 \\
0.10 & 11.9 & 90.0 & 84.0 & 0 \\
0.05 & 0 & 91.0 & 66.0 & 0 \\
0.02 & 0 & 31.0 & 51.0 & 0 \\
0.01 & 0 & 0 & 0 & 0 \\
\hline
\end{tabular}

Experimental size: 50 mites/group, 2 groups. Assay: clip method. Observation time: 24 h. Temperature: $25^{\circ} \mathrm{C}$.

centration $\left(\mathrm{LC}_{50}\right)$ value was $0.246 \mathrm{~g} / \mathrm{m}^{2}$. The mortalities of $\beta$ dolabrin were $91.0 \%$ and $31.0 \%$ at $0.05 \mathrm{~g} / \mathrm{m}^{2}$ and $0.02 \mathrm{~g} / \mathrm{m}^{2}$, respectively, and its $\mathrm{LC}_{50}$ value was $0.02 \mathrm{~g} / \mathrm{m}^{2}$. Table 2 shows that the mortalities of $\gamma$-thujaplicin at $0.05 \mathrm{~g} / \mathrm{m}^{2}$ and 0.02 $\mathrm{g} / \mathrm{m}^{2}$ were $66.0 \%$ and $51.0 \%$, respectively, and its $\mathrm{LC}_{50}$ value was $0.02 \mathrm{~g} / \mathrm{m}^{2}$. All three compounds showed higher insecticidal activity than $N, N$-diethyl- $m$-toluamide (DEET, $\mathrm{LC}_{50}: 0.79$ $\mathrm{g} / \mathrm{m}^{2}$ ), which was used as a positive control. As few effective insecticidal agents on mites have yet been developed, compounds with lower toxicity to these insects are most desirable. In this respect, the strong insecticidal activity of the three compounds on T. putrescentiae should be emphasized. The insecticidal activity of $\beta$-dolabrin and $\gamma$-thujaplicin on this insect is reported for the first time in this paper.

The insecticidal activity of hinokitiol, $\beta$-dolabrin and $\gamma$ thujaplicin on $C$. formosanus was investigated according to the usual method. As shown in Table 3, the three compounds exhibited strong insecticidal activities against this insect, although their activities were much lower than that of commercial chloropyrifos $\left(\mathrm{LC}_{50}: 0.00016 \mathrm{~g} / \mathrm{m}^{2}\right)$. The mortalities of hinokitiol at $0.1 \mathrm{~g} / \mathrm{m}^{2}$ were $50 \%$ and $100 \%$ at $24 \mathrm{~h}$ and $48 \mathrm{~h}$, respectively, and its $L_{50}$ value was $0.07 \mathrm{~g} / \mathrm{m}^{2}$. The mortality of $\beta$-dolabrin at $48 \mathrm{~h}$ was $95 \%$ at $0.1 \mathrm{~g} / \mathrm{m}^{2}$ and its $\mathrm{LC}_{50}$ value was $0.05 \mathrm{~g} / \mathrm{m}^{2}$. Table 3 shows that the mortality of $\gamma$-thujaplicin at $48 \mathrm{~h}$ was $100 \%$ at $0.1 \mathrm{~g} / \mathrm{m}^{2}$, its $\mathrm{LC}_{50}$ value being $0.05 \mathrm{~g} / \mathrm{m}^{2}$. Thus, strong insecticidal activity against $C$. formosanus was found not only in hinokitiol, but also in $\beta$ dolabrin and $\gamma$-thujaplicin, suggesting that such activity against this insect is apparently common in hinokitiol-related compounds. Although the insecticidal activity of tropolone with the basic skeleton in common with hinokitiol on C. formosanus has been reported in the short patent $t^{5)}$ no detailed 
Table 3. Insecticidal Activity of Hinokitiol, $\beta$-Dolabrin and $\gamma$-Thujaplicin on Coptotermes formosanus

\begin{tabular}{|c|c|c|c|}
\hline \multirow{2}{*}{ Compound } & \multirow{2}{*}{$\begin{array}{l}\text { Concentra- } \\
\text { tion }\left(\mathrm{g} / \mathrm{m}^{2}\right)\end{array}$} & \multicolumn{2}{|c|}{ Mortality (\%) } \\
\hline & & $24 \mathrm{~h}$ & $48 \mathrm{~h}$ \\
\hline \multirow[t]{6}{*}{ Hinokitiol } & 1.00 & 100 & 100 \\
\hline & 0.20 & 100 & 100 \\
\hline & 0.10 & 50 & 100 \\
\hline & 0.05 & 40 & 50 \\
\hline & 0.02 & 10 & 20 \\
\hline & 0.01 & 0 & 0 \\
\hline \multirow[t]{6}{*}{$\beta$-Dolabrin } & 1.00 & 100 & 100 \\
\hline & 0.20 & 100 & 100 \\
\hline & 0.10 & 40 & 95 \\
\hline & 0.05 & 0 & 11 \\
\hline & 0.02 & 0 & 0 \\
\hline & 0.01 & 0 & 0 \\
\hline \multirow[t]{6}{*}{$\gamma$-Thujaplicin } & 1.00 & 100 & 100 \\
\hline & 0.20 & 100 & 100 \\
\hline & 0.10 & 20 & 100 \\
\hline & 0.05 & 10 & 32 \\
\hline & 0.02 & 0 & 11 \\
\hline & 0.01 & 0 & 5 \\
\hline \multirow[t]{5}{*}{ Chloropyrifos } & 0.00050 & 100 & 100 \\
\hline & 0.00025 & 60 & 100 \\
\hline & 0.00010 & 25 & 75 \\
\hline & 0.00005 & 10 & 40 \\
\hline & 0.00001 & 0 & 0 \\
\hline
\end{tabular}

Experimental size: 10 insects/group, 3 groups. Temperature: $25^{\circ} \mathrm{C}$.

toxic studies including $\mathrm{LC}_{50}$ value have yet been done on its insecticidal activity against termites. The insecticidal activity of $\beta$-dolabrin and $\gamma$-thujaplicin is reported for the first time in this paper.

Hinokitiol-acetate did not show antifungal activity or insecticidal effect on the wood-rotting fungi (data not shown). A similar phenomenon was found in the inhibition of metalloproteases $^{8)}$ and antimicrobial activity, ${ }^{8)}$ suggesting that at least part of the mechanism of biological activity of hinokitiol-related compounds might be due to the metal chelation between the carbonyl group at $\mathrm{C}-1$ and the hydroxyl group at $\mathrm{C}-2$ in their tropolone skeletons. However, it is premature to conclude that the mechanism of all biological activities of hinokitiol-related compounds is due to metal chelation between the carbonyl group at $\mathrm{C}-1$ and the hydroxyl group at $\mathrm{C}-2$ in tropolone skeleton in their molecules, because $\beta$-dolabrin did not show the inhibitory activity toward thermolysin among test metalloproteases. ${ }^{8)}$ Further studies to determine another mechanism of the biological activity of hinokitiol-related compounds are in progress.

In the present study, hinokitiol, $\beta$-dolabrin and $\gamma$-thujaplicin, the constituents of $T$. dolabrata SiEB. et ZuCC. var hondai MAKINO were found to show not only antifungal activity on wood-rotting fungi, but also insecticidal activity on the noxious insects, $T$. putrescentiae and $C$. formosanus. These findings seem to be closely related to the fact that Konjikido, which was built of T. dolabrata SiEB. et ZucC. var hondai MAKINO, kept itself free of harm by wood-rotting fungi and noxious insects for a long eight hundred year period. Considering that few lower toxic physiological active substances have yet been discovered, such a broad spectrum of biological activities of hinokitiol-related compounds is of great importance.

Further studies are necessary on the synergistic effect of biological activities of these hinokitiol-related compounds to learn the reasons for the long endurance of Konjiki-do.

Acknowledgement The authors wish to express their gratitude to Takasago Int. Corp., for providing $\gamma$-thujaplicin.

\section{REFERENCES}

1) Tada T., Nakatsuka T., Mokuzai Gakkaishi, 14, 344-345 (1968).

2) Campbell R. B., Robertson J. M., Chem. Ind. (London), 1952, 12661267.

3) Hara H., Japan Kokai Tokkyo Koho, 01242508 (Oct. 16, 1989).

4) Nozoe T., Bull. Chem. Soc. Jpn., 11, 295-298 (1936).

5) Fukada M., Japan Kokai Tokkyo Koho, 100696 (Oct. 9, 1972).

6) Dewar M.J.S., Nature (London), 155, 50-51 (1945).

7) Erdltman H., Gripenberg J., Nature (London), 161, 179 (1948).

8) Inamori Y., Shinohara S., Tsujibo H., Okabe T., Morita Y., Sakagami Y., Kumeda Y., Ishida N., Biol. Pharm. Bull., 22, 990-993 (1999).

9) Nozoe T., Takase K., Ogata M., Chem. Ind. (London), 1957, 1070.

10) Nomura M., Maeda T., Fujiwara Y., Yamamoto R., Sugiura M., Shibata M., Yukagaku, 44, 309-315 (1955).

11) Katagiri Y., J. Jpn. Soc. Int. Med., 44, 32-40 (1955).

12) Ootomo Y., Okabe T., Saito K., Japan. Kokai Tokkyo Koho, JP 0190 , 104 [Chem. Abstr., 111, 148877 y (1989)].

13) Saito K., Ootomo Y., Okabe T., Japan. Kokai Tokkyo Koho, JP 0190 , 103 [Chem. Abstr., 111, $148877 x$ (1989)]. 